Published in final edited form as:

Cancer. 2017 February 15; 123(4): 583-591. doi:10.1002/cncr.30367.

\title{
Informed decision making prior to PSA screening: Initial results using the American Cancer Society (ACS) Decision Aid (DA) among medically underserved men
}

\section{Mehmet Ilker Gokce, MD,}

The University of Texas MD Anderson Cancer Center Department of Urology

\section{Xuemei Wang, MS,}

The University of Texas MD Anderson Cancer Center Department of Biostatistics

\section{Jacqueline Frost,}

The University of Texas MD Anderson Cancer Center Department of Urology

\section{Pamela Roberson,}

The University of Texas MD Anderson Cancer Center Department of Urology

\section{Robert J. Volk, PhD,}

Professor, The University of Texas MD Anderson Cancer Center Department of Health Services Research, Division of Cancer Prevention and Population Sciences

\section{Durado Brooks, MD, MPH,}

Cancer Control Interventions, The American Cancer Society, Inc

Steven E Canfield, MD, and

University of Texas Medical School at Houston, Division of Urology

\section{Curtis Pettaway, MD}

Professor, The University of Texas MD Anderson Cancer Center Department of Urology

\section{Abstract}

Corresponding Author: Curtis A. Pettaway MD, Address: 1155 Pressler Street, 77030, Houston, Texas. cpettawa@ mdanderson.org Phone: +1 (713) 4829138 Fax: (713) 794-4824.

Conflict of interest disclosures: None of the authors have any conflict.

Authors' contribution:

Conceptualization-Curtis Pettaway, Robert J. Volk.

Methodology — Curtis Pettaway, Robert J. Volk, Durado Brooks.

Software- N/A

Formal analysis - Xuemei Wang, Mehmet I. Gokce.

Investigation- Jackie Frost, Pamela Roberson, Steven E Canfield.

Resources-Curtis Pettaway, Robert J. Volk.

Data curation- Jackie Frost, Pamela Roberson, Steven E Canfield.

Writing - original draft-Curtis Pettaway, Mehmet I. Gokce.

Writing - review and editing — Curtis Pettaway, Robert J. Volk, Durado Brooks, Xuemei Wang, Mehmet I. Gokce, Steven E Canfield.

Visualization-Curtis Pettaway, Mehmet I. Gokce.

Supervision- N.A.

Project administration — Curtis Pettaway, Jackie Frost, Pamela Roberson, Steven E Canfield.

Funding acquisition-Curtis Pettaway 
Background-The American Cancer Society (ACS) recommends men have the opportunity to make an informed decision about screening for prostate cancer (Pca). The ACS developed a unique decision aid (ACS-DA), for this purpose. However, to date studies evaluating efficacy of the ACS-DA are lacking. We evaluated the ACS-DA among a cohort of medically underserved men (MUM).

Methods-A multi-ethnic cohort of MUM ( $\mathrm{n}=285)$ was prospectively included between June 2010 and December 2014. The ACS-DA was presented in a group format. Level of knowledge on Pca was evaluated before and after the presentation. Subjects' decisional conflict and thoughts about the presentation were also evaluated. Logistic regression analyses were performed to determine factors associated with having an adequate level of knowledge.

Results-Before receiving ACS-DA, 33.1\% of the subjects were found to have adequate knowledge on Pca and this increased to $77 \%$ after receiving the DA ( $\mathrm{p}<0.0001)$. On multivariate analysis, higher education level (OR:11.19; $\mathrm{p}=0.001)$ and history of another cancer (OR:7.45;p $=0.03$ ) were found to be associated with having adequate knowledge after receiving the DA. Level of decisional conflict was low and correlated with level of knowledge after receiving DA. The majority of patients also rated the presentation as favorable and would recommend the ACS-DA to others.

Conclusions-Use of the ACS-DA was feasible among MUM and led to increased Pca knowledge. This also correlated with low levels of decisional conflict. The ACS-DA presented to groups of men may serve as a feasible tool for informed decision making in a MUM population.

\section{Keywords}

prostate cancer screening; decision aid; racial disparities; PSA screening; informed decision making

\section{Introduction}

Prostate cancer (Pca) is the most common cancer among men in the United States with an estimated 221,000 cases and 27,500 deaths in $2015 .{ }^{1}$ Screening and early detection of Pca mainly relies on PSA testing and digital rectal examination (DRE), however both of these tests are imperfect screening tools. Given the uncertainty related to the magnitude of benefit in mortality reduction versus harms caused by screening the U.S. Preventive Services Task Force (USPSTF) has recommended against PSA screening for the general population. ${ }^{2}$ The American Cancer Society (ACS) recommends that men should learn about the potential benefits and harms of screening and decide whether screening is right for them. ${ }^{3}$ Similarly, The American Urological Association (AUA) has recommended against routine screening and recommended shared decision-making for men age 55 to 69 years based on a man's values and preferences. ${ }^{4}$

Decision aids (DAs) are tools developed to educate patients about possible benefits and harms of a medical condition and help them with their decision on potential options. ${ }^{5-7}$ DAs for screening of Pca have been developed and their role in increasing patients' level of knowledge, decreasing decisional conflict and impact on screening behaviors have been evaluated in a number of studies. ${ }^{8-26}$ Results of these studies mainly show an increased level 
of knowledge, but decreased decisional conflict could not be established in some of the studies. ${ }^{13,14,26}$ In 2010, the ACS developed a unique DA, The ACS Prostate Cancer Early Detection Decision Aid (ACS-DA), to aid in providing the essential components of information related to discussing the risks and benefits of prostate cancer early detection. The DA was developed to support their recommendations for the early detection of prostate cancer. ${ }^{3}$ We are unaware of subsequent publications utilizing the DA to evaluate its performance in promoting informed screening decisions.

In this study we evaluated the efficacy of the ACS-DA in group of medically underserved men (MUM) who were candidates for prostate cancer screening. We also wanted to assist them with defining their preferences. Herein we extend our prior observations among MUM while also assessing compliance with follow-up recommendations among indigent subjects who were engaged in the Harris Health Care System in Texas.

\section{Materials and methods}

\section{Participants and recruitment}

Subjects were prospectively included in the study from June 2010 through December 2014. The target population was an indigent male population between 40-70 years of age who were patients within the Harris Health Care System (HHS) in Harris County, Texas. The Settegast Clinic within the HHS was the recruitment site for the project and serves a largely medically underserved African American and Hispanic population.

Men were invited to participate in a prostate cancer education session in one of two ways 1) Men visiting the Settegast clinic for other reasons were invited by flyer to participate in a prostate cancer education and early detection session using the ACS DA. 2) Clinic physicians who were aware that the free education sessions were available and referred men to participate in the sessions.

\section{Development of The ACS - DA}

The DA was developed by ACS staff and volunteers in conjunction with the publication of the 2010 ACS guideline for prostate cancer early detection. ${ }^{3}$ The 2010 guideline recommends an informed decision-making approach for men who may be eligible for PSA based screening, and the manuscript includes a section detailing key information on the potential benefits and harms of PSA screening that should be shared with patients as part of the informed decision making discussion. The ACS Pca guideline development committee also recommended that ACS develop a simple DA to assist clinicians with this discussion. ${ }^{3}$

The DA was developed by ACS staff and the guideline committee's informed decision making expert (RV), with ongoing feedback from the guideline development committee. The ACS-DA content was written at a 5th grade reading level. Prostate cancer statistics and other numeric information were presented in a simplified fashion through the use of graphics and illustrations. The near-final version of the decision aid then underwent a qualitative evaluation by 31 men of diverse racial and ethnic (40\% African American, 40\% Caucasian, $20 \%$ Hispanic) origins. Two-thirds of the men had incomes $<\$ 25,000$ annually, and onethird were judged to have marginal or poor literacy. After reading the draft DA the men 
underwent one-on-one interviews designed to assess understanding of important facts about Pca screening, readability, perceived biases in the presentation of the information, usefulness of the information, and the main idea - i.e. Pca testing is a choice and each man should decide whether testing is right for him. Overall, respondents viewed the DA very positively, judged that the information on benefits and harms was presented in a balanced manner, and believed that after reading it they had a heightened awareness of and increased information about prostate cancer and testing for the disease. These reviewers provided a number of suggested edits and modifications that were incorporated into the final version of the ACSDA (See Supplemental files 1 and 2 for the focus group summary of findings and the final decision aid).

\section{Data collection}

Patient data were collected prospectively under an Institutional Review Board (IRB) approved Tissue/Data collection protocol related to procuring serum/tissue/data among medically underserved men considering early detection for prostate cancer. Data were retrospectively analyzed using a second protocol specific IRB approval related to the assessment of the ACS decision aid. Demographic data including age, race, level of education, type of insurance, smoking, occupational risk factors, previous Pca screening, family history of Pca and lower urinary tract symptoms were collected. Patients were subsequently given a questionnaire of 11 questions (see supplement file 3) to determine their baseline knowledge about Pca. The questionnaire was modified from two previous studies. ${ }^{27,28}$ Patients who answered at least 8 of the 11 survey questions correctly were designated as having adequate Pca knowledge. Subjects were then provided the ACS-DA using a power-point presentation and Pca knowledge was tested a second time. Of note we made the decision to utilize a power point version of the decision aid in order to facilitate group education sessions and to potentially reduce barriers to participating. The presentation was given by a Harris Health Education Specialist who was not involved as a part of the research team. The sessions included from 2-14 men with an average attendance of approximately 8 men.

After the DA presentation subjects were asked about their decision to undergo screening. Additionally they were asked to complete a ten question Decisional Conflict Scale which assesses uncertainty, whether subjects felt informed, had clarity on the information, and felt supported. ${ }^{29}$ The Decisional Conflict Scale was scored from 0 to 100 with a higher score indicating higher level of decisional conflict. Patients with a score of $\preceq 5$ were accepted as having low decisional conflict. Another 5 question survey to evaluate the presentation focusing on the amount of information given, length of the presentation, clarity and balance of information as to whether the presentation appeared to favor screening or not was also given. Finally, patients were asked to answer three questions on their personal opinions about a Pca diagnosis, possible regret about their decision on getting tested, and future loss of erectile functions if they had treatment. The first question was, 'If you had prostate cancer, would you want to know?', the second question was 'If you decided to not be tested for prostate cancer, and then you later developed prostate cancer, would you regret your decision?', and the third question was 'If you were to lose your ability to have an erection, what would it mean to you?' 


\section{Screening and early detection procedures}

Patients who decided to get screened underwent serum Prostate Specific Antigen (PSA) testing, and digital rectal examination (DRE) free of charge. Patients with an abnormal PSA level (defined as $\geq 2.5 \mathrm{ng} / \mathrm{ml}$ ) and/or abnormal DRE (presence of induration and/or frank nodules) were contacted to provide them with a clinic appointment for further counseling and possibly prostate biopsy.

\section{Statistical analysis}

Patient characteristics were summarized using median (range) for continuous variables and frequency (percentage) for categorical variables. The agreement between pre- and post-test scores were assessed using McNemar's test. Univariate and multivariate logistic regression analyses were performed to assess the association between having adequate knowledge (i.e., correctly answered $>/=8$ out of 11 questions) and other patient characteristics. Exact logistic regression analysis was performed when some cells formed by the outcome and categorical predictor variable had no observations. The Fisher's exact test was used to analyze the association of Decisional conflict score and pre- and post-presentation level of knowledge. All statistical analyses were performed in SAS 9.3.

\section{Results}

Two hundred and eighty-five patients were included in the study. The mean ( \pm SD) age of the population was $57 \pm 7.9$ years (range: $35-84$ ). Characteristics of the population are summarized in table 1 . AA men comprised $73.1 \%$ of the population and $75.8 \%$ of the participants had the equivalent of a high school or less degree of education. The median income of the cohort was $<\$ 15,000$.

Before receiving the DA, Pca knowledge was evaluated in 239 patients; 79 (33.1\%) were shown to have adequate knowledge about Pca (i.e., >=8 correct answers). The median number of correct answers was 6 (range: 0-11). After receiving the DA 226 patients took the posttest and 174 (77\%) of these patients were shown to have adequate knowledge with median number of correct answers of 9 (range: 1-11). The improvement in the proportion of patients having adequate Pca knowledge was statistically significant $(\mathrm{p}<0.0001)$.

None of the patient characteristics were found to be associated with having adequate knowledge before receiving the DA. However, having an education level higher than high school (OR: 10.15, 95\% CI: $2.38-43.38, \mathrm{p}=0.002$ ) and having history of another type of cancer (OR: 6.43, 95\% CI:1.34 - Inf, p=0.04) were found to be associated with having adequate knowledge after receiving the DA in the univariate logistic regression analysis. The results of logistic regression analysis are summarized in table 2 . These two factors were then included in a multivariate logistic regression analysis and both level of education (OR: 11.19, 95\% CI: $2.61-47.93, \mathrm{p}=0.001)$ and having history of another type of cancer (OR: $7.45,95 \%$ CI:1.52 - Inf, $\mathrm{p}=0.03$ ) were found to be significantly associated with adequate knowledge after receiving the DA.

After receiving the DA, the patients' decision to undergo screening could be evaluated in 218 subjects. Two hundred and six (94.5\%), 8 (3.7\%), and 4 (1.8\%) of the patients, 
respectively, stated they wanted to be tested, were unsure, or did not want to be tested for Pca. The mean $( \pm$ SD) Decisional Conflict Score of the population was $7.9 \pm 14.5$ and the mean $( \pm$ SD) scores of the Uncertainty, Informed, Values clarity, and Support subscales were $3.5 \pm 12.5,12.7 \pm 24.9,6.7 \pm 19.7$, and $6.9 \pm 17.2$ respectively. The Decisional Conflict Scale score was found to have a significant correlation with the post-presentation level of knowledge in the total score and all subscales except uncertainty and support subscales. The results are summarized in table 3 .

Most patients also rated the presentation favorably in terms of amount, length, clarity, and balance of information and would recommend to others. However patients were also asked about their opinion of the presentation in terms of its balance and $43.4 \%$ of the patients stated that it was clearly slanted to favor screening. The questions and summary of answers are presented in table 4 .

Patients' responses to the questions on their values were as follows: 212 of the 218 (97.2\%) of the patients stated that they would like to know if they had Pca; 189 of the $217(87.1 \%)$ patients stated that they would greatly regret or have some regret about their decision to not get tested I they were diagnosed with Pca later; and 46 of the 216 (21.3\%) patients stated that loss of erectile function would be a minor adjustment for them, whereas $25 \%$ of them stated that they might never adjust to it and $53.7 \%$ stated that it would be bad but they could adjust to it.

Two hundred eighty-one men (98.5\%) ultimately signed an informed consent to have a PSA test performed as a part of the Prostate Outreach Project (POP) enrollment. The median serum PSA level was $0.9 \mathrm{ng} / \mathrm{ml}$ (range: 0.1-10.7). DRE was performed in 180 men with 29 (16.1\%) abnormal. Either an abnormal DRE or abnormal serum PSA was noted in 51 of the $281(18.1 \%)$ patients that underwent PSA testing and/or DRE. Four of the patients were lost to follow up and remaining 47 patients were contacted and given an appointment. Thirtyseven $(78.7 \%)$ of these 47 patients kept their appointment. An additional 10 patients were given an appointment for their lower urinary tract symptoms and 9 of these patients also kept their appointment. The overall patient compliance rate was $80.7 \%$ with a follow-up appointment. After the clinic visit, prostate biopsy was performed in 16 patients and six of 16 biopsied patients (37.5\%) exhibited Pca. Reasons for not undergoing biopsy included a repeat DRE with normal results, physician or patient preference in order to follow serial serum PSA levels over time.

\section{Discussion}

PSA based screening in the general population has been debated and the USPSTF has recommended against routine PSA screening. ${ }^{2}$ Both the ACS and AUA recommend informed decision making before Pca screening. ${ }^{3,4}$ The ACS developed a DA for this particular purpose but to our knowledge reports of its use have not been published to date. In this study we used the ACS-DA in the form of a presentation and the results support significant improvement in the patients' level of knowledge on harms and benefits of Pca screening, was well accepted by the patients, and maintained low decisional conflict scores in a population of MUM. 
In our cohort, $33.1 \%$ of the patients were found to have adequate baseline knowledge and this rate increased to $77 \%$ after the presentation. Increased knowledge on Pca screening after DA has been reported previously in a number of studies. ${ }^{8}, 10-15,17-21,23-26,30,31$ The level of increase in Pca knowledge depends on many factors such as baseline level of knowledge, educational status of the population, the type of DA (web based, print or presentation) and the content of the DA. For instance, in the study by Ashorobi et al. we previously reported that $17 \%$ of the patients were found to have adequate level of knowledge and this increased to $58 \%$ after utilizing a video format educational tool that was written at a 10th-grade reading level. ${ }^{31}$ In the present study, the ACS-DA, which was developed for 5th grade reading level, was given to patients in a unique form of a power-point presentation and mediated higher rate of patients with adequate knowledge. While both studies were performed in the community setting and had over 60\% African American male participants, the current study represented men who presented at a health clinic for services. The prior study by Ashorobi included a more unselected cohort of AA underserved males in that $40 \%$ had no physician and $50 \%$ were uninsured. Thus, differences in baseline and post-test knowledge were likely mediated by multiple factors including the study population, educational content, reading level, and method of presentation.

In the study by Magnus et al. income level and having a family member with history of Pca were found to be associated with higher level of Pca knowledge. ${ }^{32}$ Similarly in the study by Weinrich et al., family income was identified as being associated with knowledge on Pca screening in a population of men mostly AA origin. ${ }^{33}$ In the study by Ashorobi et al., AA race, education level greater than high school, positive family history of Pca, possession of insurance, and prior Pca testing were found to be associated with adequate level of knowledge. ${ }^{31}$ However, in the current study we could not identify any of the factors associated with adequate level of knowledge. This may be associated with relatively lower number of patients in the current study. Additionally, we accepted 8 correct answers of 11 questions as adequate knowledge but it was 8 out 10 in the study by Ashorobi et al. ${ }^{31}$ Therefore, the threshold for adequate knowledge was somehow lower in the current study and this may explain the disparity in the baseline rate of patients with adequate knowledge and the factors associated with adequate knowledge.

Patient education related to Pca screening is especially important for men in the medically underserved populations, particularly those of Hispanic and AA ethnicity. In a population based survey, rates of utilization of Pca screening tests were evaluated. Men of Hispanic and AA ethnicity in addition to men with less than a high school education or a low income level were found to have the lowest prevalence of Pca screening. ${ }^{34}$ Miller et al. also noted that contrary to the general population, the rate of clinically insignificant low stage Pca does not increase in the low income, uninsured population. ${ }^{35}$ Therefore, under-detection and undertreatment are still significant problems in this population. This is especially relevant given that the studies that the USPSTF used as a data source for their recommendations had few AA men. ${ }^{2}$ Given this dilemma it becomes even more important the AA and other underserved populations be provided with information about the risks and benefits of Pca early detection so that they can make informed decisions about testing. 
After the presentation, patients' decisional conflict levels were found to be low. This was concordant with the previous studies that reported decreased decisional conflict after receiving the DA. ${ }^{8}, 10-13,15,18,22,30$ Decisional conflict levels were also correlated with the level of knowledge after the presentation in that those with adequate knowledge also tended to have low decisional conflict levels. In their study Taylor et al. reported mean decisional conflict scores of 10.7 and 11.4 for their groups of patients who received print and web based DA's. ${ }^{22}$ Mean decisional conflict score after the presentation was 7.9 in the present study and this was slightly lower but consistent with the finding of Taylor et al. ${ }^{22}$

The amount of information given in the presentation, length of presentation, and clarity of the information were all scored satisfactory by the patients. Also $96.4 \%$ of the patients stated that they would recommend the presentation to others facing this decision. However, we noted that $43.4 \%$ of the patients stated that the presentation was clearly slanted to favor testing. This contrasted with the nearly one half of the patients who stated that it was completely balanced. This was not explained by different presenters as over $90 \%$ of the sessions were provided by the same education specialist. Given that the material was presented to the men versus self-administered we also cannot dissect whether this was related to the presenter or the material. A similar schism was recorded in the qualitative evaluation of the self-administered version of the DA during its' development. Most participants perceived the tool as presenting the pros and cons of screening in a balanced fashion, but others felt the tool was "pro-screening". This issue raises an item for further study to determine the optimal use of the ACS DA among various cohorts of men.

An abnormal screening event was observed in $18.1 \%$ of the patients and this was similar to the $14 \%$ rate in the study by Ashorobi et al. ${ }^{31}$ However patient compliance was $80.7 \%$ in the current study, double the $40 \%$ rate of adequate follow up in the study by Ashorobi et al. ${ }^{31}$ One obvious difference in the two populations was that in the current study subjects were already engaged with the healthcare system when they were recruited to be a part of the study. This was not the case in our prior study as 50\% were uninsured and $40 \%$ had no physician. While we provided navigated assistance in attempting to bring the subjects from the study reported by Ashorobi et al into the system barriers included, incorrect contact information, unaware of being lost to follow-up, or stating that they wanted to see other physicians. As the subjects in the current study were already engaged in a healthcare system follow-up was facilitated.

While the current study provides unique evidence regarding the use of the ACS-DA for informed decision making it has several limitations. The DA was given as a PowerPoint presentation rather than by self-administration. While we believed this would improve compliance and the ease of providing the information to this MUM cohort we may have introduced a bias related to presenting the material itself. Another important point is that patients' decisional conflict levels were evaluated only after the presentation. We do not know the patients' decisional conflict levels before the intervention, and it is possible many had already made a decision about screening. Notwithstanding, the data supports that the DA did improve knowledge and that such an improvement in knowledge was associated with lower decisional conflict. 
Another important limitation of the study relates to the selection of patients for prostate cancer early detection. Both the American Urologic Association and the American Cancer Society recommend screening be avoided in men with less than a ten-year life expectancy. Comorbid conditions among this study population included Diabetes, Heart Disease, hypertension, and prior stroke. While the subjects were all ambulatory and did not appear to have any obvious limitations during their clinic visit we cannot be certain that all of the subjects had an anticipated 10 year life expectancy. Thus some of our patients may have eventually undergone screening inappropriately. Given that a portion were not referred by their primary care providers this may have affected that group of men more significantly. Based on current guidelines we agree that the DA is optimally used in conjunction with the physician among a population of men referred by their physicians that have an anticipated life expectancy of greater than 10 years. The appropriately educated patient and physician can then make a final decision about whether to be screened or not. This is relevant as the DA itself does not provide information on how life expectancy might affect a decision for prostate cancer screening but does urge subjects to speak with their physicians about screening. In this regard there are several online tools that can assist physicians in determining the likelihood of a patient's survival at 5-10 years factoring in their medical history. ${ }^{(36-38)}$

Notwithstanding the above limitations, this is the first study reporting on the use of ACSDA. The successful use of the DA among an indigent cohort of men of low educational level speaks to its potential utility as an educational tool in busy outpatient settings where primary care physicians may feel overburdened or uncomfortable with their existing knowledge base to counsel their patients. ${ }^{39}$ Future studies should prospectively evaluate the optimal method of administration of the DA among diverse populations of men while measuring baseline variables related to existing knowledge and attitudes about Pca detection and treatment, as well as decisional conflict.

\section{Conclusions}

Use of the ACS-DA in the form of a presentation among a multiethnic underserved cohort was feasible in a clinic setting. The ACS-DA presentation lead to increased Pca knowledge and this was directly correlated with low levels of decisional conflict with respect to Pca early detection. These results suggest that the ACS-DA given in the form of a presentation was a feasible tool for informed decision making among this cohort and should be further evaluated as a model for educating men about Pca early detection prior to testing.

\section{Supplementary Material}

Refer to Web version on PubMed Central for supplementary material.

\section{Acknowledgments}

Funding sources:
1. National Cancer Institute, U54 CS 96300/U54 CA 96297
2. TEX US TOO prostate cancer support group 


\section{References}

1. Siegel RL, Miller KD, Jemal A. Cancer statistics, 2015. CA Cancer J Clin. 2015; 65:5-29. [PubMed: 25559415]

2. Moyer VA. Force USPST. Screening for prostate cancer: U.S. Preventive Services Task Force recommendation statement. Ann Intern Med. 2012; 157:120-134. [PubMed: 22801674]

3. Wolf AM, Wender RC, Etzioni RB, et al. American Cancer Society guideline for the early detection of prostate cancer: update 2010. CA Cancer J Clin. 2010; 60:70-98. [PubMed: 20200110]

4. Carter HB, Albertsen PC, Barry MJ, et al. Early detection of prostate cancer: AUA Guideline. J Urol. 2013; 190:419-426. [PubMed: 23659877]

5. O'Connor AM, Stacey D, Rovner D, et al. Decision aids for people facing health treatment or screening decisions. Cochrane Database Syst Rev. 2001:CD001431. [PubMed: 11686990]

6. Stacey D, Bennett CL, Barry MJ, et al. Decision aids for people facing health treatment or screening decisions. Cochrane Database Syst Rev. 2011:CD001431. [PubMed: 21975733]

7. Volk RJ, Hawley ST, Kneuper S, et al. Trials of decision aids for prostate cancer screening: a systematic review. Am J Prev Med. 2007; 33:428-434. [PubMed: 17950409]

8. Allen JD, Othus MK, Hart A Jr, et al. A randomized trial of a computer-tailored decision aid to improve prostate cancer screening decisions: results from the Take the Wheel trial. Cancer Epidemiol Biomarkers Prev. 2010; 19:2172-2186. [PubMed: 20716619]

9. Chan EC, McFall SL, Byrd TL, et al. A community-based intervention to promote informed decision making for prostate cancer screening among Hispanic American men changed knowledge and role preferences: a cluster RCT. Patient Educ Couns. 2011; 84:e44-51. [PubMed: 21237611]

10. Evans R, Joseph-Williams N, Edwards A, et al. Supporting informed decision making for prostate specific antigen (PSA) testing on the web: an online randomized controlled trial. J Med Internet Res. 2010; 12:e27. [PubMed: 20693148]

11. Frosch DL, Bhatnagar V, Tally S, Hamori CJ, Kaplan RM. Internet patient decision support: a randomized controlled trial comparing alternative approaches for men considering prostate cancer screening. Arch Intern Med. 2008; 168:363-369. [PubMed: 18299490]

12. Gattellari M, Ward JE. Does evidence-based information about screening for prostate cancer enhance consumer decision-making? A randomised controlled trial. J Med Screen. 2003; 10:2739. [PubMed: 12790313]

13. Gattellari M, Ward JE. A community-based randomised controlled trial of three different educational resources for men about prostate cancer screening. Patient Educ Couns. 2005; 57:168182. [PubMed: 15911190]

14. Krist AH, Woolf SH, Johnson RE, Kerns JW. Patient education on prostate cancer screening and involvement in decision making. Ann Fam Med. 2007; 5:112-119. [PubMed: 17389534]

15. Lepore SJ, Wolf RL, Basch CE, et al. Informed decision making about prostate cancer testing in predominantly immigrant black men: a randomized controlled trial. Ann Behav Med. 2012; 44:320-330. [PubMed: 22825933]

16. Myers RE, Daskalakis C, Cocroft J, et al. Preparing African-American men in community primary care practices to decide whether or not to have prostate cancer screening. J Natl Med Assoc. 2005; 97:1143-1154. [PubMed: 16173330]

17. Partin MR, Nelson D, Radosevich D, et al. Randomized trial examining the effect of two prostate cancer screening educational interventions on patient knowledge, preferences, and behaviors. $\mathbf{J}$ Gen Intern Med. 2004; 19:835-842. [PubMed: 15242468]

18. Rubel SK, Miller JW, Stephens RL, et al. Testing the effects of a decision aid for prostate cancer screening. J Health Commun. 2010; 15:307-321. [PubMed: 20432110]

19. Schapira MM, VanRuiswyk J. The effect of an illustrated pamphlet decision-aid on the use of prostate cancer screening tests. J Fam Pract. 2000; 49:418-424. [PubMed: 10836772]

20. Stamatiou K, Skolarikos A, Heretis I, et al. Does educational printed material manage to change compliance with prostate cancer screening? World J Urol. 2008; 26:365-373. [PubMed: 18421460] 
21. Taylor KL, Davis JL 3rd, Turner RO, et al. Educating African American men about the prostate cancer screening dilemma: a randomized intervention. Cancer Epidemiol Biomarkers Prev. 2006; 15:2179-2188. [PubMed: 17119044]

22. Taylor KL, Williams RM, Davis K, et al. Decision making in prostate cancer screening using decision aids vs usual care: a randomized clinical trial. JAMA Intern Med. 2013; 173:1704-1712. [PubMed: 23896732]

23. Volk RJ, Spann SJ, Cass AR, Hawley ST. Patient education for informed decision making about prostate cancer screening: a randomized controlled trial with 1-year follow-up. Ann Fam Med. 2003; 1:22-28. [PubMed: 15043176]

24. Watson E, Hewitson P, Brett J, et al. Informed decision making and prostate specific antigen (PSA) testing for prostate cancer: a randomised controlled trial exploring the impact of a brief patient decision aid on men's knowledge, attitudes and intention to be tested. Patient Educ Couns. 2006; 63:367-379. [PubMed: 16875796]

25. Wilt TJ, Paul J, Murdoch M, Nelson D, Nugent S, Rubins HB. Educating men about prostate cancer screening. A randomized trial of a mailed pamphlet. Eff Clin Pract. 2001; 4:112-120. [PubMed: 11434074]

26. Myers RE, Daskalakis C, Kunkel EJ, et al. Mediated decision support in prostate cancer screening: a randomized controlled trial of decision counseling. Patient Educ Couns. 2011; 83:240-246. [PubMed: 20619576]

27. O'Dell KJ, Volk RJ, Cass AR, Spann SJ. Screening for prostate cancer with the prostate-specific antigen test: are patients making informed decisions? J Fam Pract. 1999; 48:682-688. [PubMed: 10498074]

28. Radosevich DM, Partin MR, Nugent S, et al. Measuring patient knowledge of the risks and benefits of prostate cancer screening. Patient Educ Couns. 2004; 54:143-152. [PubMed: 15288907]

29. O'Connor AM. Validation of a decisional conflict scale. Med Decis Making. 1995; 15:25-30. [PubMed: 7898294]

30. Williams RM, Davis KM, Luta G, et al. Fostering informed decisions: a randomized controlled trial assessing the impact of a decision aid among men registered to undergo mass screening for prostate cancer. Patient Educ Couns. 2013; 91:329-336. [PubMed: 23357414]

31. Ashorobi OS, Frost J, Wang X, et al. Prostate Cancer Education, Detection, and Follow-Up in a Community-Based Multiethnic Cohort of Medically Underserved Men. Am J Mens Health. 2015

32. Magnus M. Prostate cancer knowledge among multiethnic black men. J Natl Med Assoc. 2004; 96:650-656. [PubMed: 15160980]

33. Weinrich SP, Seger R, Miller BL, et al. Knowledge of the limitations associated with prostate cancer screening among low-income men. Cancer Nurs. 2004; 27:442-453. [PubMed: 15632783]

34. Tran TY, McGillen K, Cone EB, Pareek G. Triple D Score is a reportable predictor of shockwave lithotripsy stone-free rates. J Endourol. 2015; 29:226-230. [PubMed: 25046472]

35. Miller DC, Litwin MS, Bergman J, et al. Prostate cancer severity among low income, uninsured men. J Urol. 2009; 181:579-583. discussion 583-574. [PubMed: 19100580]

36. http://www.cdc.gov/nchs/fastats/life-expectancy.htm.

37. https://www.livingto100.com/calculator.

38. http://eprognosis.ucsf.edu/calculators/ - /.

39. Tasian GE, Cooperberg MR, Cowan JE, et al. Prostate specific antigen screening for prostate cancer: knowledge of, attitudes towards, and utilization among primary care physicians. Urol Oncol. 2012; 30:155-160. [PubMed: 20800514] 


\section{Table 1}

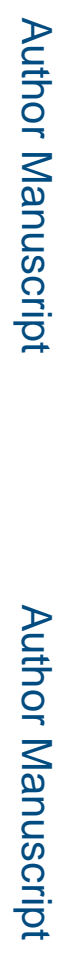

General characteristics of the population

\begin{tabular}{|c|c|c|c|}
\hline Variable & & $\mathbf{N}$ & $\%$ \\
\hline \multirow[t]{6}{*}{ Race } & African American & 179 & 73.1 \\
\hline & Caucasian & 14 & 5.7 \\
\hline & Hispanic & 50 & 20.4 \\
\hline & Asian & 1 & 0.4 \\
\hline & Other & 1 & 0.4 \\
\hline & Missing & 40 & \\
\hline \multirow[t]{3}{*}{ Insurance } & Yes & 204 & 87.2 \\
\hline & No & 30 & 12.8 \\
\hline & Missing & 51 & \\
\hline \multirow[t]{7}{*}{ Education } & 8th grade or less & 26 & 10.3 \\
\hline & 9 th to 11 th grade & 48 & 19.0 \\
\hline & high school & 117 & 46.4 \\
\hline & technical school & 27 & 10.7 \\
\hline & associates dgree & 23 & 9.1 \\
\hline & bachelors degree & 11 & 4.4 \\
\hline & Missing & 33 & \\
\hline \multirow[t]{4}{*}{ Smoking } & Yes & 83 & 33.7 \\
\hline & Previous smoker & 50 & 20.3 \\
\hline & Never smoked & 113 & 45.9 \\
\hline & missing & 39 & \\
\hline \multirow[t]{4}{*}{ Family history of $\mathrm{PCa}$} & Yes & 39 & 16.8 \\
\hline & No & 102 & 44.0 \\
\hline & Not known & 91 & 39.2 \\
\hline & Missing & 53 & \\
\hline \multirow[t]{9}{*}{ Household income } & Unknown & 32 & 15.5 \\
\hline & $<15,000$ & 115 & 55.6 \\
\hline & $15-25,000$ & 38 & 18.4 \\
\hline & $26-35,000$ & 15 & 7.2 \\
\hline & $36-45,000$ & 3 & 1,4 \\
\hline & $46-55,000$ & 2 & 1.0 \\
\hline & $56-65,000$ & 1 & 0.5 \\
\hline & $66-75,000$ & 1 & 0.5 \\
\hline & Missing & 78 & \\
\hline \multirow[t]{3}{*}{ Prostate Infection With In 1 Year } & No & 228 & 95.4 \\
\hline & Yes & 11 & 4.6 \\
\hline & Missing & 46 & \\
\hline Prostate surgery within 1 year & No & 237 & 97.9 \\
\hline
\end{tabular}




\begin{tabular}{|c|c|c|c|}
\hline Variable & & $\mathbf{N}$ & $\%$ \\
\hline & Yes & 5 & 2.1 \\
\hline & Missing & 43 & \\
\hline \multirow[t]{3}{*}{ Rectal exam within 1 year } & No & 275 & 96.5 \\
\hline & Yes & 10 & 3.5 \\
\hline & Missing & - & \\
\hline \multirow[t]{3}{*}{ PSA within 1 year } & No & 227 & 96.2 \\
\hline & Yes & 9 & 3.8 \\
\hline & Missing & 49 & \\
\hline \multirow[t]{3}{*}{ Blood in urine within 1 year } & No & 227 & 94.6 \\
\hline & Yes & 13 & 5.4 \\
\hline & Missing & 45 & \\
\hline \multirow[t]{3}{*}{ Burning on urination within 1 year } & No & 214 & 89.9 \\
\hline & Yes & 24 & 10.1 \\
\hline & Missing & 47 & \\
\hline \multirow[t]{4}{*}{ Erection problems } & Never & 108 & 49.3 \\
\hline & Sometimes & 73 & 33.3 \\
\hline & Often & 38 & 17.4 \\
\hline & Missing & 66 & \\
\hline \multirow[t]{3}{*}{ Diabetes } & No & 103 & 60.9 \\
\hline & Yes & 66 & 39.1 \\
\hline & Missing & 116 & \\
\hline \multirow[t]{3}{*}{ Heart disease } & No & 126 & 85.1 \\
\hline & Yes & 22 & 14.9 \\
\hline & Missing & 148 & \\
\hline \multirow[t]{3}{*}{ Stroke } & No & 126 & 90.6 \\
\hline & Yes & 13 & 9.4 \\
\hline & Missing & 146 & \\
\hline \multirow[t]{3}{*}{ High blood pressure } & No & 53 & 28.6 \\
\hline & Yes & 132 & 71.4 \\
\hline & Missing & 100 & \\
\hline
\end{tabular}




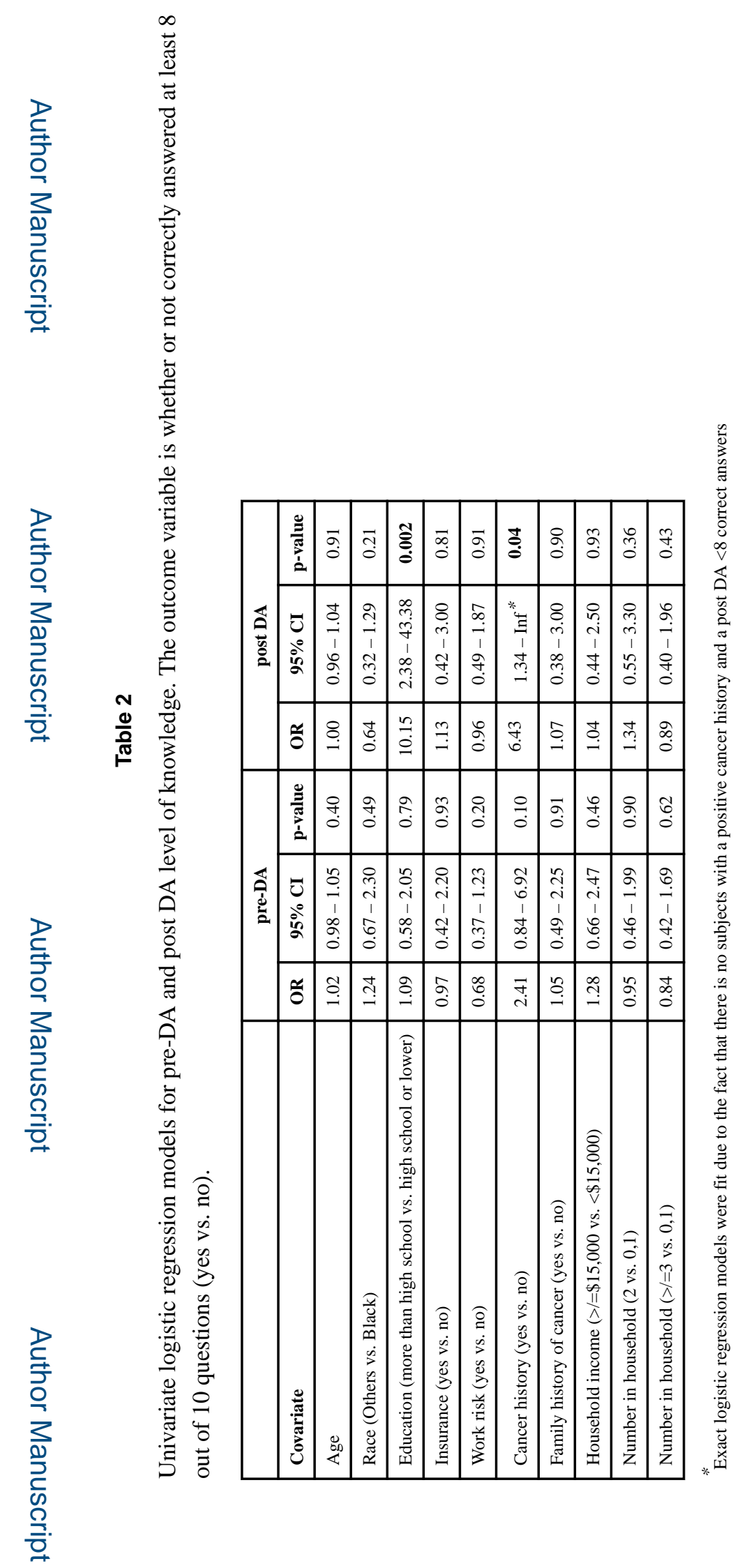

Cancer. Author manuscript; available in PMC 2018 February 15. 


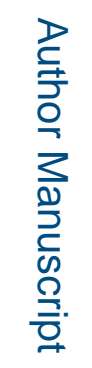

\begin{tabular}{|c|c|c|c|c|c|c|c|c|c|c|c|c|c|c|c|c|}
\hline 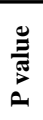 & & $\mid \begin{array}{l}\vec{\delta} \\
\dot{\Xi} \\
\dot{\vec{v}}\end{array}$ & & & הి & & & $\begin{array}{l}\bar{\delta} \\
\vdots \\
\dot{0} \\
\vec{v}\end{array}$ & & & 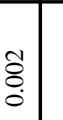 & & & $\begin{array}{l}\infty \\
0 \\
0 \\
0\end{array}$ & & \\
\hline 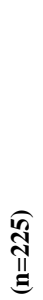 & 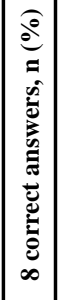 & & $\begin{array}{l}0 \\
\dot{0} \\
0 \\
\vec{\sigma} \\
0\end{array}$ & $\mid \begin{array}{c}f \\
f \\
e \\
= \\
=\end{array}$ & & $\begin{array}{l}c \\
\overline{5} \\
\vdots \\
5 \\
-\end{array}$ & $\begin{array}{c}\hat{d} \\
\dot{d}\end{array}$ & & 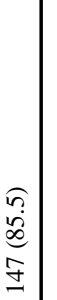 & 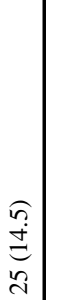 & & 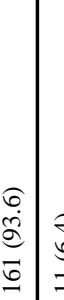 & $\begin{array}{l}\underset{f}{\stackrel{f}{e}} \\
= \\
\exists\end{array}$ & $\begin{array}{l}\infty \\
\infty \\
\infty \\
\underline{n}\end{array}$ & & 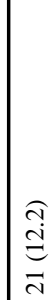 \\
\hline 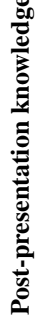 & 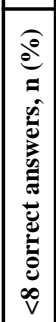 & & $\begin{array}{c}n \\
n \\
n \\
o \\
o\end{array}$ & $\begin{array}{l}n \\
\mathfrak{n} \\
d \\
n \\
n\end{array}$ & & $\begin{array}{l}\hat{n} \\
\hat{i} \\
\hat{\sigma} \\
o \\
\dot{q}\end{array}$ & 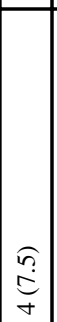 & & 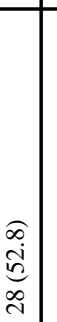 & \begin{tabular}{l}
$\widehat{T}$ \\
\multirow{y}{y}{} \\
\cline { 1 - 1 } \\
\cline { 1 - 1 }
\end{tabular} & & 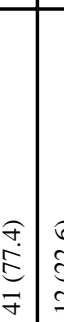 & $\begin{array}{l}\underset{\sigma}{d} \\
\underset{d}{d} \\
\underline{I}\end{array}$ & $\begin{array}{l}7 \\
5 \\
5 \\
7\end{array}$ & & $\begin{array}{l}\underset{0}{i} \\
\text { d } \\
\text { I }\end{array}$ \\
\hline
\end{tabular}

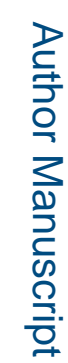
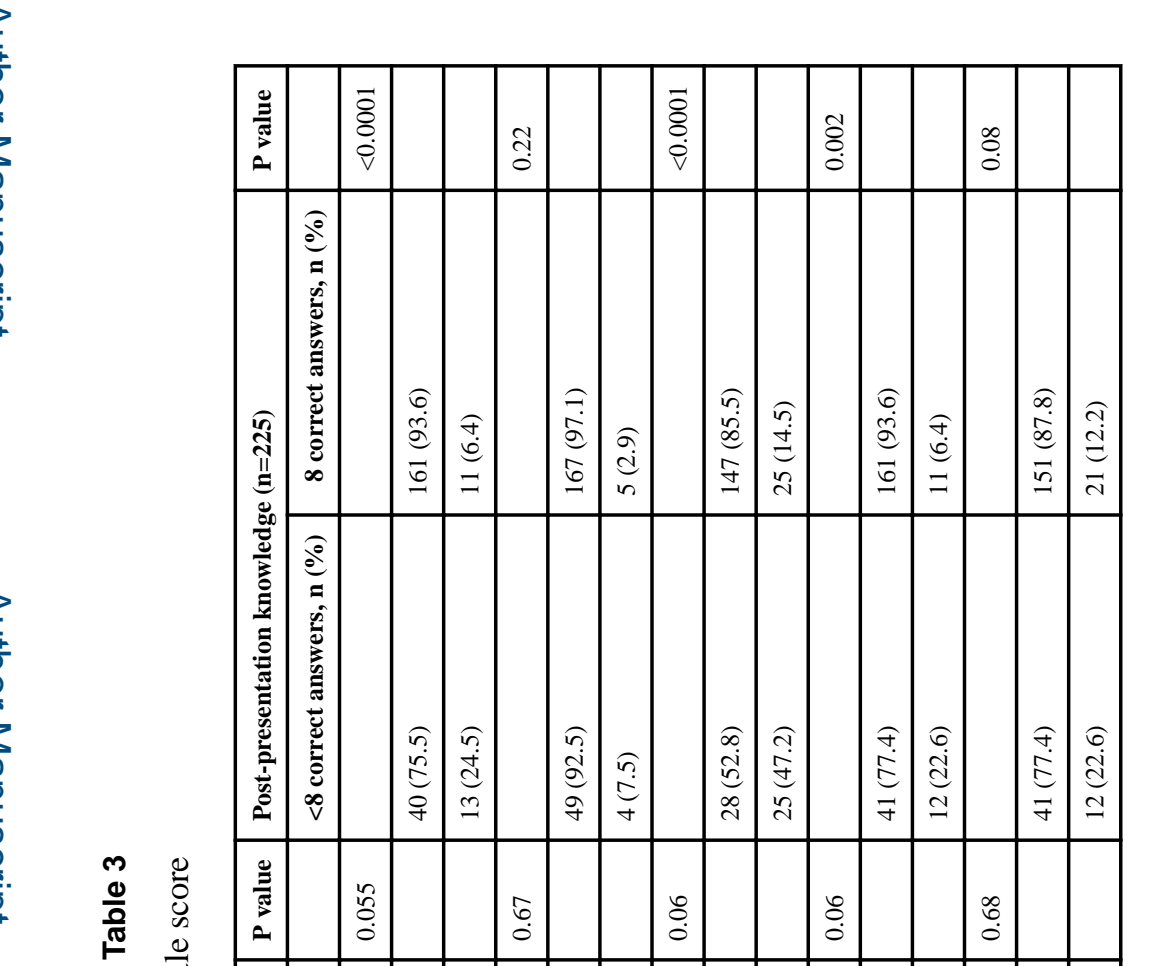



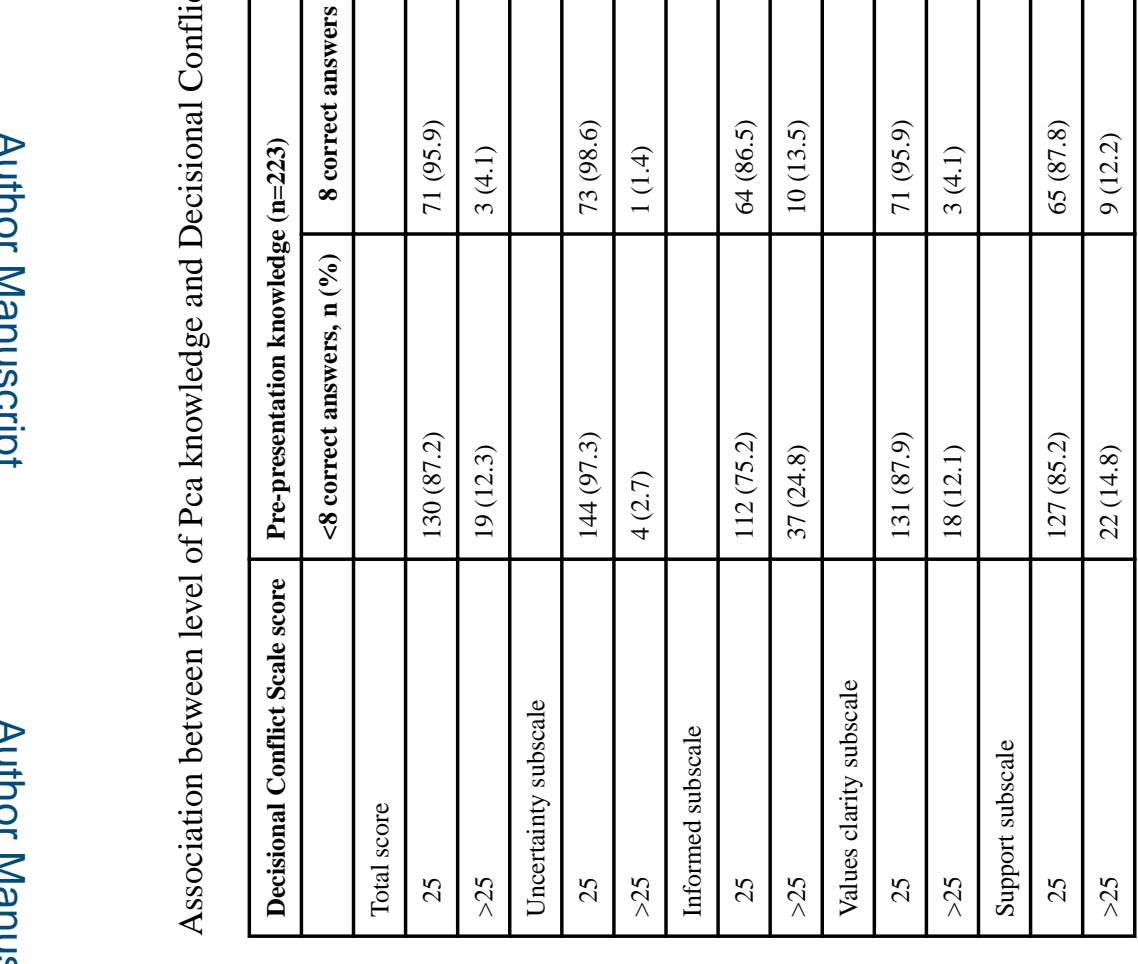

Cancer. Author manuscript; available in PMC 2018 February 15. 


\section{Table 4}

Patient evaluation of the ACS-DA presentation

\begin{tabular}{|c|c|c|}
\hline Questions & Answers & Number $(\%)$ \\
\hline \multirow[t]{5}{*}{ How would you rate the amount of information given in the presentation? } & Much less than wanted & $14(6.3)$ \\
\hline & Little less than wanted & $5(2.3)$ \\
\hline & About right & $162(73.3)$ \\
\hline & Little more than wanted & $7(3.2)$ \\
\hline & Much more than wanted & $33(14.9)$ \\
\hline \multirow[t]{5}{*}{ How would you rate the length of the presentation? } & Much too long & $6(2.7)$ \\
\hline & Little too long & $9(4.1)$ \\
\hline & About right & $196(88.7)$ \\
\hline & Should have been a little longer & $5(2.3)$ \\
\hline & Should have been much longer & $5(2.3)$ \\
\hline \multirow[t]{4}{*}{ How clearly were the issues presented in the presentation? } & Everything clear & $173(78.6)$ \\
\hline & Most things clear & $36(16.4)$ \\
\hline & Some things unclear & $11(5.0)$ \\
\hline & Most things unclear & - \\
\hline \multirow[t]{5}{*}{ How would you rate the presentation? } & Clearly slanted to favor testing & $96(43.4)$ \\
\hline & Slightly slanted to favor testing & $8(3.6)$ \\
\hline & Completely balanced & $110(49.8)$ \\
\hline & Slightly slanted to favor not testing & $7(3.2)$ \\
\hline & Clearly slanted to favor not testing & - \\
\hline \multirow[t]{3}{*}{ Would you recommend the presentation to other people facing this decision? } & Yes & $213(96.4)$ \\
\hline & No & $1(0.5)$ \\
\hline & Not sure & $7(3.2)$ \\
\hline
\end{tabular}

